Correspondence: Lilit Khachatryan, Global Fund Projects Coordinating Team, Ministry of Health, Yerevan, Armenia.

Tel. +374.91328651

E-mail: 1.khachatryan@moh.am

Key words: Default; case fatality; treatment failure; home-based treatment; directly observed treatment (DOT); family DOT.

Acknowledgements: The authors thank the national TB counterparts of the National Center of Pulmonology of the Ministry of Health of Armenia for nominating and providing data for this study, the Ministry of Health of Armenia for authorization to participate in this study, and the secretariat of the European TB Research Initiative (ERI-TB) at the WHO Regional Office for Europe for organizing the Structured Operational Research Training (SORT-TB) for eastern European countries supported by the USAID-WHO regional partnership project to End TB in eastern Europe. SORT-TB curriculum was an adaptation of the UNICEF/UNDP/World Bank/WHO Special Programme for Research and Training in Tropical Diseases (TDR) SORT IT course (https://www.who.int/tdr/capacity/ strengthening/sort/en/) to the eastern European context. Our deep gratitude also goes to Prof. Giovanni Battista Migliori, Director of WHO Collaborating Centre for TB and Lung Disease, for his incredible support and encouragement, Mrs. Lena Nanushyan, Deputy Minister of Health of Armenia, Ms. Anush Khachatryan, Head of Monitoring and Evaluation Department of the National Center of Pulmonology of Armenia, for her valuable support in data collection and clearance, and my beloved family for their love and patience.

Contributions: $\mathrm{LK}$ was the principal investigator; $\mathrm{LK}, \mathrm{AM}, \mathrm{RG}, \mathrm{AD}, \mathrm{AK}$, $\mathrm{KA}, \mathrm{HH}$, study aims and methods concept; KD, statistical analyses performing; LK, data collection and literature review; LK, KA, KD, analysis design and execution; LK, AM, RG manuscript first draft; $\mathrm{AD}$, $\mathrm{AK}, \mathrm{KA}, \mathrm{HH}$, reviewed the paper critically and provided substantial revisions to the initial version of the manuscript. All authors approved the final version of the paper submitted to the journal.

Conflict of interest: The authors declare no conflict of interest.

Funding: This study was funded by the United States Agency for International Development. The funding body had no role in study design, data collection and analysis, decision to publish, or preparation of the manuscript.

Disclaimer: The authors alone are responsible for the views expressed in this publication and they do not necessarily represent the decisions or policies of the World Health Organization.

Ethics approval: Permission to carry out the study was obtained from the Ministry of Health in Armenia. National ethics approval was granted by Ethics Review Board of the Healthcare and Development Initiative, Armenia. Exemption from an ethics review was also received from the World Health Organization Research Ethics Review Committee based in Geneva, Switzerland (ERC.0003316/10.03.2020). A waiver of informed consent was granted by ethics review bodies, as the study collected and analysed de-identified routine recording and reporting data.

Received for publication: 10 July 2020.

Accepted for publication: 11 August 2020.

OWorld Health Organization 2021.

All rights reserved. The WHO Regional Office for Europe has granted the Publisher permission for the reproduction of this article.

Licensee PAGEPress, Italy

Monaldi Archives for Chest Disease 2021; 91:1677

doi: 10.4081/monaldi.2021.1677

Open access statement: In accordance with WHO's open-access publication policy for all work funded by $\mathrm{WHO}$ or authored/co-authored by WHO staff members, the WHO retains the copyright of this publication through a Creative Commons Attribution IGO licence (http://creativecommons.org/licenses/by/3.0/igo/legalcode) which permits unrestricted use, distribution and reproduction in any medium provided the original work is properly cited.

\section{Factors associated with unfavourable treatment outcomes among people with rifampicin- resistant tuberculosis in Armenia, 2014-2017}

\author{
Lilit Khachatryan', Ruzanna Grigoryan², \\ Andrei Dadu ${ }^{3}$, Ajay M.V. Kumar, ${ }^{4,5,6}$, \\ Kristina Akopyan ${ }^{2,7}$, Kostyantyn Dumchev ${ }^{8}$, \\ Hasmik Harutyunyan ${ }^{1}$, Alberto Matteelli ${ }^{9}$
}

${ }^{1}$ Global Fund Projects Coordinating Team, Ministry of Health, Yerevan, Armenia; ${ }^{2}$ Tuberculosis Research and Prevention Center, Yerevan, Armenia; ${ }^{3}$ World Health Organization, Regional Office for Europe, Copenhagen, Denmark; ${ }^{4}$ International Union Against Tuberculosis and Lung Disease, Paris, France; ${ }^{5}$ International Union Against Tuberculosis and Lung Disease, South-East Asia Office, New Delhi, India; ${ }^{6}$ Yenepoya Medical College, Yenepoya (Deemed to be University), Mangaluru, India;

${ }^{7}$ National Center for Infectious Diseases, Yerevan, Armenia; ${ }^{8}$ Ukrainian Institute on Public Health Policy, Kyiv, Ukraine; ${ }^{9}$ University of Brescia, Brescia, Italy

\section{Abstract \\ Rifampicin-resistant/multidrug-resistant tuberculosis} (RR/MDR-TB) is recognized as a major public health concern globally. In Armenia, the proportion of RR/MDR-TB is increasing among all people affected with TB. We conducted a nationwide cohort study involving analysis of programmatic data to investigate the rates of and factors associated with unfavourable treatment outcomes among patients with RR/MDR-TB registered by the national TB programme from 2014 to 2017 in Armenia. We used Cox regression to identify factors associated with the outcome. Among 451 RR/MDR-TB patients, 80\% were men and median age was 46 years. Of them, $53(11.8 \%)$ had extensively drug-resistant tuberculosis (XDR-TB) and 132 (29.3\%) had preXDR-TB. Almost half $(224,49.7 \%)$ of the patients had unfavourable treatment outcome, which included $26.8 \%$ loss to follow-up (LTFU), 13.3\% failures and 9.5\% deaths. In multivariable analysis, people with pre-XDR-TB [adjusted hazard ratio [aHR] 3.13, 95\% confidence intervals [CI] 2.16-4.55] and XDRTB (aHR 4.08, 95\% CI 2.45-6.79) had a higher risk of unfavourable outcomes. Patients receiving home-based treatment $(71 / 451,15.7 \%)$ and treatment with new drugs $(172 / 451,38.1 \%)$ had significantly lower risk (aHR $0.45,95 \%$ CI $0.28-0.72$ and aHR $0.26,95 \%$ CI $0.18-0.39$ ) of unfavourable treatment outcome. The proportion of MDR-TB patients reaching favourable treatment outcome in Armenia was substantially lower than the recommended level $(75 \%)$. The most common treatment outcome was LTFU indicating the need for further assessment of underlying 
determinants. Home-based treatment looks promising and future studies are required to see if expanding it to all RR/MDR-TB patients is feasible and cost-effective.

\section{Introduction}

Tuberculosis (TB) remains one of the biggest public health problems worldwide despite the huge efforts to fight the disease. The World Health Organization's (WHO) End TB strategy aims to reduce TB incidence by $90 \%$ by 2035 relative to 2015 levels. However, this may not be achievable at the current rate of annual decline of $2 \%$ [1]. One of the obstacles towards the target is the spread of drug-resistant TB. In 2018, about half a million people developed rifampicin-resistant and/or multidrug-resistant tuberculosis (RR/MDR-TB) worldwide. It was estimated that $3.4 \%$ of new and $18 \%$ of previously treated TB patients had RR/MDR-TB globally. These proportions were larger for patients from the former Soviet countries with more than $50 \%$ of previously treated patients having RR/MDR-TB [1]. To address the MDR-TB situation in the WHO European region, a consolidated Action Plan was developed and adopted by member states in 2016 [2].

Armenia is one of the 18 high-priority countries for MDR-TB in the WHO European Region. Though the overall TB incidence is declining, the rate of decline is much higher among drug-susceptible TB compared to RR/MDR-TB. Thus, the proportion of all TB patients with RR/MDR-TB is increasing (from $11 \%$ in 2013 to $14 \%$ in 2018) [3].

The most important indicator of RR/MDR-TB management the treatment success rate which includes cured and treatment completed outcomes - has never reached the WHO target of $75 \%$ in Armenia [4]. It ranged between $42 \%$ and $58 \%$ for the cohort enrolled in the study period in 2014-2017 [5]. The most frequent unfavourable treatment outcomes were loss to follow-up followed by failure and death [3].

Globally, many risk factors for unfavourable treatment outcomes of RR/MDR-TB patients have been identified [6]. These include HIV co-infection, diabetes mellitus, poor treatment adherence, delay in TB treatment initiation and history of previous TB treatment [6-17]. Evidence from Armenia on this topic is limited: previous studies have reported socio-economic factors such as education, income and occupation, and adverse drug events as the key factors for poor outcomes among MDR-TB patients $[9,18,19]$. However, these studies were not nationally representative. The identification of determinants of unfavourable treatment outcomes for RR/MDR-TB was one of the national research priorities outlined by the National TB Programme (NTP) in Armenia [20]. In line with this, we systematically investigated occurrence of, and factors associated with unfavourable treatment outcomes among patients with RR/MDR-TB registered by the NTP from 2014 to 2017 in Armenia.

\section{Materials and Methods}

\section{Study design}

This was a nationwide cohort study involving review of routine programme data.

\section{Setting}

TB prevention and care in Armenia has been coordinated by the NTP under the Ministry of Health since 2006. All TB services including diagnosis and treatment of RR/MDR-TB are provided free of charge. The government covers almost $53 \%$ of the TB health expenditure and the remaining is funded by international donors (mostly by the Global Fund against AIDS, TB and Malaria) [21]. Treatment of drug-resistant TB is individualized based on the drug-susceptibility pattern and is decided by the national committee of experts who follow the national guidelines which are in line with WHO-recommended TB and MDR-TB guidelines [22]. The all-oral regimens were introduced in the country in July 2019 with no impact on the current study population.

The new anti-tuberculosis drugs bedaquiline and delamanid were introduced in Armenia in 2013 and 2014 respectively in the framework of 'compassionate use' programme initiated by the Médecins Sans Fontieres-France. They were introduced in conventional treatment regimens of second-line anti-tuberculosis medicines in use with more toxic and less effective impact. Particularly, drug-to-drug interactions associated with the treatment of comorbidities often led to limited efficacy and safety and caused overlapping side-effects [23]. The new drugs containing treatment regimens were further approved in the framework of the End TB strategy and the national treatment guidelines since 2016. Coverage of RR/MDR-TB patients receiving new drugs gradually increased from $21 \%$ in 2013 to $75 \%$ in 2019 [3].

Directly observed treatment (DOT) was adopted as a patientsupport measure, since the launch of the NTP countrywide. The alternative patient-friendly modes of DOT include video-observed DOT and home-based DOT. Video-DOT was introduced in 2016 in RR/MDR-TB patients for the evening dose every day and all the doses on Sunday carried out centrally by the NTP medical staff. Typically, around $25 \%$ of all RR/MDR-TB patients receive videoDOT annually. Home-based DOT was introduced in 2013 covering around $15 \%$ of all patients (both drug susceptible and resistant) annually. The eligibility for home-based DOT in Armenia includes immobility (including vertebral TB), serious comorbidities (such as advanced diabetes, chronic respiratory diseases and cardiovascular disease), advanced age (older than 65 years), breastfeeding mothers and mothers having children under age five. Home-based DOT is also prescribed to patients who receive the second dose of imipenem in the evenings when the primary health care facilities are closed. A health care provider, predominantly a nurse, observes the drug intake by the patient. In addition, the TB doctors are required to visit the patient once a month to monitor the treatment progress and to detect and manage adverse drug events, if any. Home-based DOT is part of the national protocol and there are no additional transportation costs for nurses delivering drugs.

All TB patients are routinely offered HIV testing, and people with HIV-associated TB are started on antiretroviral therapy, irrespective of CD4 count or clinical staging. Testing for any other comorbidities, such as diabetes, is routinely offered by the primary health care provider.

Management of TB in the penitentiary sector is fully in line with the national guidelines: there is no difference between diagnostic and treatment algorithms in the civilian and imprisoned population. People released from prison who are still on treatment continue receiving DOT at the primary health care facilities of their residence area.

All the individual patient data are captured electronically in the 'e-TB manager' [3]. This system is operational since 2013 nationwide and captures the data from TB facilities as well as the peni- 
tentiary sector. Information about RR/MDR-TB patients on homebased care is captured in a separate MS Excel® database maintained by the NTP. The reasons for treatment interruptions and LTFU, as perceived by the treating health care providers, are captured by the monitoring department of NTP in a separate record and reported to the Ministry of Health.

\section{Study population and period}

We included all adult ( $\geq 18$ years) patients diagnosed with pulmonary and extra-pulmonary RR/MDR-TB started on second-line treatment in Armenia from January 1, 2014 to December 31, 2017. This includes patients diagnosed and managed in the penitentiary sector [24].

\section{Sources of data and data variables}

Data were extracted from two sources: 'e-TB manager' electronic system and Excel database for home-based care and were merged using unique patient identifier. The outcome of interest was a combined unfavourable treatment outcome (LTFU, death or failure). Case definition, outcome categories, recording and reporting follow the WHO guidelines (Table 1) [25]. Socio-demographic variables included: age, sex, Body Mass Index (BMI in $\mathrm{kg} / \mathrm{m}^{2}$ ), employment status, migrant status, residence area. Clinical variables included current smoking status (assessed by clinician at baseline), type and site of RR/MDR-TB, sputum smear microscopy, Xpert and culture results at baseline, type of resistance, time between diagnosis and treatment initiation, treatment modality (home-based or in-patient/outpatient) and type (with and without new drugs), HIV status and history of ART, hepatitis C virus (HCV) infection, comorbidities including diabetes and cancer. Patient who self-reported a history of leaving Armenia with a purpose to find employment abroad and staying abroad for at least three months was considered a 'migrant' irrespective of finding employment or not [26]. Current smoking was defined as smoking at least two cigarettes per day at the time of data collection.

\section{Analysis and statistics}

Socio-demographic and clinical characteristics of the cohort were described using proportions for categorical variables and mean with Standard Deviation (SD) or median as appropriate for continuous variables. Time-to-event methods were used to describe occurrence of the combined unfavourable outcome. Person-time was calculated from the date of diagnosis to the end of treatment episode. Unadjusted analysis was done using univariable Cox regression for each potential predictor. Variables significant at $\mathrm{p}<0.1$ level and key socio-demographic variables (sex, age, BMI) were included into the multivariable Cox regression model and adjusted Hazard Ratios (aHR) and 95\% Confidence Intervals (CI) were calculated. The proportional hazard assumption was verified for each variable. Data were analysed using SPSS (v23 for Windows, IBM Corporation, USA).

\section{Results}

We analysed $451 \mathrm{RR} / \mathrm{MDR}-\mathrm{TB}$ patients (Table 2). The mean age of the cohort was 46.6 years $(\mathrm{SD}=14.2)$ and study participants were predominantly males (81\%). Almost half of the cohort (44\%) was unemployed, and one-third reported history of labour migration. Less than half of the study participants (40\%) were current smokers at the time of starting treatment. Nearly all patients were tested for HIV and $\mathrm{HCV}(99 \%$ and 100\%), and infection was found in 55/445 (12\%) and 77/451 (17\%) patients, respectively. Antiretroviral treatment (ART) was started in 39 people with HIV-associated TB $(39 / 55,71 \%)$. In addition, $30 / 451$ patients $(6.7 \%)$ had diabetes.

Almost half of the study participants (47\%) had a previous history of TB treatment. There were 53 patients $(12 \%)$ with extensively drug-resistant tuberculosis (XDR-TB, resistance to fluoroquinolones and second line injectables) and 132 (29\%) patients had pre-XDR-TB (resistance to fluoroquinolones or injectables). Only $38 \%$ of cases received treatment with new anti-tuberculosis drugs (bedaquiline, delamanid). Treatment was initiated within the first two days from diagnosis in $77 \%$ of all diagnosed patients, and $5 \%$ initiated treatment after two or more weeks after diagnosis. Less than a quarter of TB patients $(71 / 451,16 \%)$ received homebased treatment. Almost half of the participants (224/451, 49\%) had unfavourable treatment outcomes. These included 121 patients $(27 \%)$ who were lost to follow-up, 60 (13\%) with treatment failure, and $43(10 \%)$ who died. Median time to outcome was 22.9 months [interquartile range (IQR) $20.2-24.6$ on $25^{\text {th }}$ and $75^{\text {th }}$ centiles] for cure, 21.9 (IQR 20.0-24.2) for treatment completion, 2.9

Table 1. Definitions of treatment outcomes among RR/MDR-TB patients in Armenia.

\begin{tabular}{|c|c|c|}
\hline \multirow[t]{2}{*}{ Favourable treatment outcome } & Cured & $\begin{array}{l}\text { Treatment completed as recommended by the national policy without evidence of failure } \\
\text { AND three or more consecutive cultures taken at least } 30 \text { days apart are negative after the } \\
\text { intensive phase. }\end{array}$ \\
\hline & Treatment completed & $\begin{array}{l}\text { Treatment completed as recommended by the national policy without evidence of failure } \\
\text { BUT no record that three or more consecutive cultures taken at least } 30 \text { days apart are } \\
\text { negative after the intensive phase. }\end{array}$ \\
\hline Treatment success rate & & The sum of cured and treatment completed \\
\hline \multirow[t]{3}{*}{ Unfavourable treatment outcome } & Lost to follow-up & A patient whose treatment was interrupted for 2 consecutive months or more. \\
\hline & Failed & $\begin{array}{l}\text { Treatment terminated or need for permanent regimen change of at least two anti-TB } \\
\text { drugs because of lack of conversion by the end of the intensive phase, or bacteriological } \\
\text { reversion in the continuation phase after conversion to negative, or evidence of additional } \\
\text { acquired resistance to fluoroquinolones or second-line injectable drugs, or adverse drug } \\
\text { reactions. }\end{array}$ \\
\hline & Died & A patient who dies for any reason during the course of treatment. \\
\hline Not evaluated & & A patient for whom no treatment outcome is assigned \\
\hline
\end{tabular}

RR/MDR-TB, rifampicin resistant and/or multi-drug resistant tuberculosis. 
(IQR 0.5-5.7) for death, 8.3 (IQR 3.7-14.2) for failure, 6.2 (IQR 2.9-13.2) for loss to follow-up.

The proportion of unfavourable outcomes was highest among XDR-TB patients $(32 / 53,60 \%)$, followed by pre-XDR-TB (76/132, 58\%) and RR/MDR-TB (106/246, 43\%). The probability of unfavourable outcome was higher among patients with history of labour migration (58\% compared to $46 \%$ in patients without this history, $\mathrm{p}=0.023$ ). Drug resistance, treatment modality (home- or facility-based) and type (with or without new drugs), previous TB treatment, presence of HCV or diabetes, smoking, employment, labour migration, sex and age met criteria for inclusion into the multivariable model. In multivariable analysis, people with preXDR-TB (aHR 3.13, 95\% CI 2.16-4.55) and XDR-TB (aHR 4.08, $95 \%$ CI 2.45-6.79) had a higher risk of unfavourable outcomes. Any episode of previous treatment increased the risk of the unfavourable outcome (aHR 1.36, 95\% CI 1.01-1.83). Patients receiving home-based treatment $(71 / 451,16 \%)$ and treatment with new drugs $(172 / 451,38 \%)$ had significantly lower risk (aHR 0.45 , 95\% CI $0.28-0.72$ and aHR $0.26,95 \%$ CI $0.18-0.39$ respectively) of the unfavourable treatment outcome (Table 3 ).

\section{Discussion}

Resistance to anti-tuberculosis drugs represents an important health challenge in Armenia. We found that almost half of the study participants had an unfavourable treatment outcome, which was approximately 3.1 and 4.0 times more likely among pre-XDRTB and XDR-TB patients, after controlling for the effects of other key socio-demographic and clinical variables. Conversely, homebased treatment and treatment with new drugs were strong protec-

Table 2. Social-demographic and clinical characteristics of RR/MDR-TB patients enrolled on treatment from civilian and penitentiary sectors in Armenia (2014-2017).

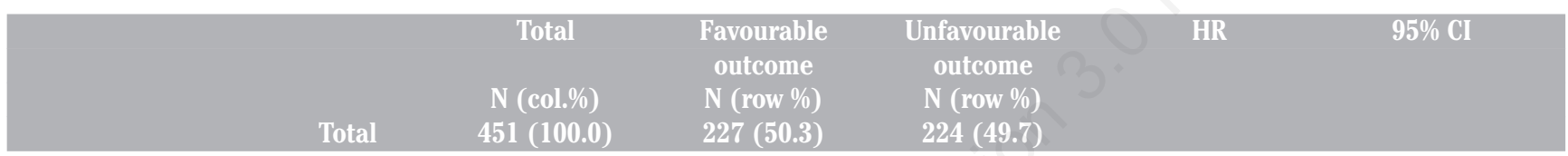

Sex

\begin{tabular}{|c|c|c|c|c|c|}
\hline $\begin{array}{l}\text { Female } \\
\text { Male }\end{array}$ & $\begin{array}{c}87(19.3) \\
364(80.7)\end{array}$ & $\begin{array}{c}52(59.8) \\
175(48.1)\end{array}$ & $\begin{array}{c}35(40.2) \\
189(51.9)\end{array}$ & $\begin{array}{l}\text { Ref } \\
1.36\end{array}$ & $(0.95-1.95)$ \\
\hline $\begin{array}{l}\text { Age } \\
<=30 \\
31-45 \\
46-60 \\
>61\end{array}$ & $\begin{array}{l}61(13.5) \\
157(34.8) \\
153(33.9) \\
80(17.7)\end{array}$ & $\begin{array}{l}39(63.9) \\
81(51.6) \\
66(43.1) \\
41(51.3)\end{array}$ & $\begin{array}{l}22(36.1) \\
76(48.4) \\
87(56.9) \\
39(48.8)\end{array}$ & $\begin{array}{l}\text { Ref } \\
1.36 \\
1.70 \\
1.49\end{array}$ & $\begin{array}{l}(0.85-2.19) \\
(1.06-2.71) \\
(0.88-2.51)\end{array}$ \\
\hline $\begin{array}{l}\text { BMI } \\
\text { Underweight }(<18.5) \\
\text { Normal }(18.5-24.9) \\
\text { Overweight or obese }(25.0+)\end{array}$ & $\begin{array}{c}141(31.8) \\
262(59.0) \\
41(9.2)\end{array}$ & $\begin{array}{c}66(46.8) \\
137(52.3) \\
23(56.1)\end{array}$ & $\begin{array}{l}75(53.2) \\
125(47.7) \\
18(43.9)\end{array}$ & $\begin{array}{l}1.15 \\
\text { Ref } \\
0.85\end{array}$ & $\begin{array}{l}(0.87-1.53) \\
(0.52-1.4)\end{array}$ \\
\hline $\begin{array}{l}\text { Currently employed } \\
\text { No } \\
\text { Yes } \\
\text { Unknown }\end{array}$ & $\begin{array}{l}200(44.3) \\
130(28.8) \\
121(26.8)\end{array}$ & $\begin{array}{l}88(44.0) \\
65(50.0) \\
74(61.2)\end{array}$ & $\begin{array}{l}112(56.0) \\
65(50.0) \\
47(38.8)\end{array}$ & $\begin{array}{l}\text { Ref } \\
0.92 \\
\mathbf{0 . 6 7}\end{array}$ & $\begin{array}{c}(0.68-1.25) \\
(\mathbf{0 . 4 8 - 0 . 9 4 )}\end{array}$ \\
\hline $\begin{array}{l}\text { Currently smoking } \\
\text { No } \\
\text { Yes } \\
\text { Unknown }\end{array}$ & $\begin{array}{l}206(45.7) \\
180(39.9) \\
65(14.4)\end{array}$ & $\begin{array}{l}109(52.9) \\
79(43.9) \\
39(60.0)\end{array}$ & $\begin{array}{l}97(47.1) \\
101(56.1) \\
26(40.0)\end{array}$ & $\begin{array}{l}\text { Ref } \\
1.22 \\
0.88\end{array}$ & $\begin{array}{l}(0.92-1.61) \\
(0.57-1.35)\end{array}$ \\
\hline $\begin{array}{l}\text { Type of RR/MDR-TB } \\
\text { New } \\
\text { Previously treated }\end{array}$ & $\begin{array}{l}239(53.0) \\
212(47.0)\end{array}$ & $\begin{array}{c}132(55.2) \\
95(44.8)\end{array}$ & $\begin{array}{l}107(44.8) \\
117(55.2)\end{array}$ & $\begin{array}{l}\text { Ref } \\
1.18\end{array}$ & $(0.9-1.53)$ \\
\hline $\begin{array}{l}\text { HIV and ART } \\
\text { HIV negative } \\
\text { HIV positive not on ART } \\
\text { HIV positive on ART }\end{array}$ & $\begin{array}{l}390(87.6) \\
16(3.6) \\
39(8.8)\end{array}$ & $\begin{array}{l}199(51.0) \\
6(37.5) \\
19(48.7)\end{array}$ & $\begin{array}{l}191(49.0) \\
10(62.5) \\
20(51.3)\end{array}$ & $\begin{array}{l}\text { Ref } \\
1.44 \\
1.12\end{array}$ & $\begin{array}{c}(0.76-2.72) \\
(0.7-1.77)\end{array}$ \\
\hline $\begin{array}{l}\text { Migrant status } \\
\text { No } \\
\text { Yes }\end{array}$ & $\begin{array}{l}322(71.4) \\
129(28.6)\end{array}$ & $\begin{array}{c}173(53.7) \\
54(41.9)\end{array}$ & $\begin{array}{l}149(46.3) \\
75(58.1)\end{array}$ & $\begin{array}{l}\text { Ref } \\
1.28\end{array}$ & $(0.97-1.69)$ \\
\hline $\begin{array}{l}\text { Sector } \\
\text { Civilian } \\
\text { Penitentiary }\end{array}$ & $\begin{array}{c}439(97.3) \\
12(2.7)\end{array}$ & $\begin{array}{c}220(50.1) \\
7(58.3)\end{array}$ & $\begin{array}{c}219(49.9) \\
5(41.7)\end{array}$ & $\begin{array}{l}\text { Ref } \\
0.70\end{array}$ & $(0.29-1.71)$ \\
\hline $\begin{array}{l}\text { Treatment with new drugs } \\
\text { No } \\
\text { Yes }\end{array}$ & $\begin{array}{l}279(61.9) \\
172(38.1)\end{array}$ & $\begin{array}{c}134(48.0) \\
93(54.1)\end{array}$ & $\begin{array}{l}145(52.0) \\
79(45.9)\end{array}$ & $\begin{array}{c}\text { Ref } \\
\mathbf{0 . 6 8}\end{array}$ & $(0.51-0.89)$ \\
\hline
\end{tabular}


tive factors, reducing the risk of unfavourable outcome by $55 \%$ and $74 \%$, respectively.

In our cohort, the RR/MDR-TB treatment success rate was similar to the data from the WHO European Region and far from reaching the WHO European targets [1]. The largest share of unfavourable treatment outcomes was due to LTFU, recorded in more than a quarter of the whole cohort and about half of those with unfavourable treatment outcomes. Given the high rate of LTFU as well as its potential relatedness to social and economic conditions of the country, we recommend further study the determinants for LTFU.

Resistance to anti-tuberculosis drugs - whether it is primary or acquired - poses a significant challenge for reaching the recommended treatment success in RR/MDR-TB patients [6,27]. This problem has been widely investigated in various settings $[6,7,28,29]$. Longer duration of RR/MDR-TB treatment often leads to poor treatment adherence and development of more extensive resistance to antibiotics as does previous history of treatment associated with unfavourable treatment outcomes $[6,13,14,18,28,30,31]$. Additionally, injectables may often cause adverse events [32-34] and may further contribute to interruptions and treatment failures. This problem has been recognized and addressed in Armenia through a national policy change by introducing all oral treatment regimens in 2019. The nationwide impact of this recent change is yet to be assessed [22].

Our findings confirm that home-based DOT, implemented by health care providers, is a protective factor against unfavourable treatment outcome. This has important policy/practice implications for RR/MDR-TB management in Armenia. The home-based DOT was first introduced with the support of the Global Fund in 2013 both for susceptible- and resistant-TB as an alternative to traditional DOT. The purpose was to reduce unnecessary hospitalization, its

Table 2. Continued from previous page.

\begin{tabular}{|c|c|c|c|c|c|}
\hline Total & $\begin{array}{c}\text { Total } \\
\text { N (col.\%) } \\
451(100.0)\end{array}$ & $\begin{array}{l}\text { Favourable } \\
\text { outcome } \\
\text { N (row \%) } \\
227(50.3)\end{array}$ & $\begin{array}{c}\text { Unfavourable } \\
\text { outcome } \\
\text { N (row \%) } \\
224(49.7)\end{array}$ & HR & $95 \%$ CI \\
\hline $\begin{array}{l}\text { Diabetes } \\
\text { No } \\
\text { Yes }\end{array}$ & $\begin{array}{c}421(93.3) \\
30(6.7)\end{array}$ & $\begin{array}{c}217(51.5) \\
10(33.3)\end{array}$ & $\begin{array}{c}204(48.5) \\
20(66.7)\end{array}$ & $\begin{array}{l}\text { Ref } \\
1.46\end{array}$ & $(0.92-2.31)$ \\
\hline $\begin{array}{l}\text { Cancer } \\
\text { No } \\
\text { Yes } \\
\text { Unknown } \\
\end{array}$ & $\begin{array}{c}437(96.9) \\
2(0.4) \\
12(2.7)\end{array}$ & $\begin{array}{c}217(49.7) \\
0(0.0) \\
10(83.3)\end{array}$ & $\begin{array}{c}220(50.3) \\
2(100.0) \\
2(16.7) \\
\end{array}$ & $\begin{array}{l}\text { Ref } \\
1.85 \\
\mathbf{0 . 2 3}\end{array}$ & $\begin{array}{c}(0.46-7.45) \\
(\mathbf{0 . 0 6 - 0 . 9 1 )}\end{array}$ \\
\hline $\begin{array}{l}\text { HCV } \\
\text { No } \\
\text { Yes }\end{array}$ & $\begin{array}{c}374(82.9) \\
77(17.1)\end{array}$ & $\begin{array}{l}199(53.2) \\
28(36.4)\end{array}$ & $\begin{array}{c}175(46.8) \\
49(63.6)\end{array}$ & $\begin{array}{l}\text { Ref } \\
1.36\end{array}$ & $(0.99-1.87)$ \\
\hline $\begin{array}{l}\text { Residence type } \\
\text { Rural } \\
\text { Urban } \\
\end{array}$ & $\begin{array}{l}166(36.8) \\
285(63.2)\end{array}$ & $\begin{array}{c}81(48.8) \\
146(51.2)\end{array}$ & $\begin{array}{c}85(51.2) \\
139(48.8)\end{array}$ & $\begin{array}{l}\text { Ref } \\
0.98\end{array}$ & (0.74-1.28) \\
\hline $\begin{array}{l}\text { Site of RR/MDR-TB } \\
\text { Extra-pulmonary } \\
\text { Pulmonary }\end{array}$ & $\begin{array}{c}19(4.2) \\
432(95.8)\end{array}$ & $\begin{array}{c}13(68.4) \\
214(49.5)\end{array}$ & $\begin{array}{c}6(31.6) \\
218(50.5)\end{array}$ & $\begin{array}{l}\text { Ref } \\
0.61\end{array}$ & $(0.27-1.37)$ \\
\hline $\begin{array}{l}\text { SS microscopy at baseline } \\
\text { Negative } \\
\text { Positive }\end{array}$ & $\begin{array}{l}145(32.2) \\
306(67.8)\end{array}$ & $\begin{array}{c}81(55.9) \\
146(47.7)\end{array}$ & $\begin{array}{c}64(44.1) \\
160(52.3)\end{array}$ & $\begin{array}{l}\text { Ref } \\
1.18\end{array}$ & (0.89-1.58) \\
\hline $\begin{array}{l}\text { Culture at baseline } \\
\text { Negative } \\
\text { Positive }\end{array}$ & $\begin{array}{c}23(5.1) \\
428(94.9)\end{array}$ & $\begin{array}{c}13(56.5) \\
214(50.0)\end{array}$ & $\begin{array}{c}10(43.5) \\
214(50.0)\end{array}$ & $\begin{array}{l}\text { Ref } \\
1.15\end{array}$ & $(0.61-2.18)$ \\
\hline $\begin{array}{l}\text { Time from diagnosis to treatment } \\
\text { Up to } 2 \text { days } \\
\text { 3-14 days } \\
\text { 14+ days }\end{array}$ & $\begin{array}{l}344(77.1) \\
78(17.5) \\
24(5.4)\end{array}$ & $\begin{array}{l}164(47.7) \\
50(64.1) \\
12(50.0)\end{array}$ & $\begin{array}{l}180(52.3) \\
28(35.9) \\
12(50.0)\end{array}$ & $\begin{array}{c}\text { Ref } \\
\mathbf{0 . 6 1} \\
0.83\end{array}$ & $\begin{array}{c}(\mathbf{0 . 4 1 - 0 . 9 )} \\
(0.46-1.49)\end{array}$ \\
\hline $\begin{array}{l}\text { DST result } \\
\text { Other } \\
\text { RR/MDR } \\
\text { PreXDR } \\
\text { XDR }\end{array}$ & $\begin{array}{c}20(4.4) \\
246(54.5) \\
132(29.3) \\
53(11.8)\end{array}$ & $\begin{array}{c}10(50.0) \\
140(56.9) \\
56(42.4) \\
21(39.6)\end{array}$ & $\begin{array}{l}10(50.0) \\
106(43.1) \\
76(57.6) \\
32(60.4)\end{array}$ & $\begin{array}{c}1.58 \\
\text { Ref } \\
\mathbf{1 . 4 3} \\
1.44\end{array}$ & $\begin{array}{c}(0.82-3.03) \\
(\mathbf{1 . 0 6 - 1 . 9 2 )} \\
(0.97-2.14)\end{array}$ \\
\hline $\begin{array}{l}\text { Home-based treatment } \\
\text { No } \\
\text { Yes }\end{array}$ & $\begin{array}{c}380(84.3) \\
71(15.7)\end{array}$ & $\begin{array}{c}180(47.4) \\
47(66.2)\end{array}$ & $\begin{array}{c}200(52.6) \\
24(33.8)\end{array}$ & $\begin{array}{l}\text { Ref } \\
\mathbf{0 . 5 0}\end{array}$ & $(0.33-0.76)$ \\
\hline
\end{tabular}

CI, confidence interval; SD, standard deviation; TB, tuberculosis; BMI, body mass index; RR/MDR-TB, rifampicin resistant and/or multi-drug resistant tuberculosis; SS, sputum smear; DST, drug susceptibility test; XDR, extensively resistant tuberculosis; HIV, human immunosuppression virus; ART, antiretroviral therapy; HCV, hepatitis C virus. 
related costs and subsequent transmission of TB. This concept has been supported by a number of studies which suggest that unnecessary hospitalization and reduced transmission of the disease further contribute to better infection control - a crucial factor for preventing the spread of TB infection $[8,27,35]$. The benefits of homebased DOT include also the reduction of total healthcare expenditures as a result of decreased hospitalization and reduced TB transmission.

A number of factors may explain the protective impact of home-based treatment in our cohort. Firstly, patients receiving treatment at home may have better adherence, because of the shared responsibility for taking medications between the nurse and the patient. On the one hand, the nurses typically do not miss the visits as part of their professional duty. Moreover, patients take the drugs in their own comfortable settings without any inconveniences caused by the travel to the healthcare facility. Finally, family members may also contribute to the increased adherence specially those involved in the social and psychological support programs delivered by non-governmental and civil society organizations (Armenian Red Cross Society, TB-REP 2). Nevertheless, it is worth mentioning that patients eligible for inclusion into the homebased DOT initially have a different profile and are at lower risk of LTFU. Further stratified investigation may be needed to explore all pros and cons of home-based treatment.

Considering the improved treatment outcomes, the lower cost of the treatment, and the reduced risk of the disease transmission, we recommend that the NTP considers expanding this alternative patient-friendly model of home-based care to all RR/MDR-TB patients who do not have any medical indications for hospitalization with recommended weekly visits to health care facility for better control of the adverse drug events. A pilot study assessing home treatment in a representative group of RR/MDR-TB patients, as well as studies on feasibility and cost-effectiveness would build a solid foundation for expanding the home-based DOT to all RR/MDR-TB patients in Armenia.

A randomized clinical trial by Khachadourian et al. showed that patient-centred TB care including home-based DOT had a significant impact on improved adherence and treatment outcomes for drug sensitive TB patients in Armenia [36]. Our recommendation is also in line with international evidence [35]. Ravenscroft et al. in their recent study also suggest new solutions for home-based care for TB patients [37]. In Moldova a video-observed treatment model was piloted and proven to be more effective and less costly for TB treatment [37]. This finding is also supported by the experience of Belarus and Australia - demonstrating effectiveness of video-observed treatment $[38,39]$. There are also some controversies about the consequences of the home-based treatment in the literature $[40,41]$. While some authors found that home-based treatment was safe and acceptable for both the patients and health care providers, others indicate that treating patient at home may lead to uncontrolled and missed adverse events [40,41]. This was attributed to the lack of proper patient counselling and suboptimal

Table 3. Multivariable proportional hazard model for unfavourable treatment outcomes among RR/MDR-TB patients enrolled on treatment from civilian and penitentiary sectors of Armenia (2014-2017).

\begin{tabular}{|c|c|c|c|c|}
\hline Factors & & p-value & aHR & $95 \% \mathrm{CI}$ \\
\hline Sex & $\begin{array}{l}\text { Female } \\
\text { Male }\end{array}$ & 0.464 & $\begin{array}{l}\text { (ref) } \\
1.17\end{array}$ & $(0.77-1.77)$ \\
\hline Age category & $\begin{array}{l}<=45 \text { y.o. } \\
>45 \text { y.o. }\end{array}$ & 0.125 & $\begin{array}{l}\text { (ref) } \\
1.26\end{array}$ & $(0.94-1.69)$ \\
\hline BMI & $\begin{array}{l}\text { Normal } \\
\text { Underweight } \\
\text { Overweight or obese }\end{array}$ & $\begin{array}{l}0.496 \\
0.161\end{array}$ & $\begin{array}{l}\text { (ref) } \\
1.11 \\
0.69\end{array}$ & $\begin{array}{l}(0.82-1.49) \\
(0.41-1.16)\end{array}$ \\
\hline Employment & $\begin{array}{l}\text { Unemployed } \\
\text { Employed } \\
\text { Unknown }\end{array}$ & $\begin{array}{l}0.834 \\
0.051\end{array}$ & $\begin{array}{l}\text { (ref) } \\
1.04 \\
0.62\end{array}$ & $\begin{array}{c}(0.74-1.46) \\
(0.38-1.0)\end{array}$ \\
\hline Smoking & $\begin{array}{l}\text { No } \\
\text { Yes } \\
\text { Unknown }\end{array}$ & $\begin{array}{l}0.692 \\
0.497\end{array}$ & $\begin{array}{l}\text { (ref) } \\
1.06 \\
1.24\end{array}$ & $\begin{array}{l}(0.78-1.45) \\
(0.66-2.33)\end{array}$ \\
\hline Previous TB treatment & $\begin{array}{l}\text { No } \\
\text { Yes }\end{array}$ & 0.044 & $\begin{array}{l}\text { (ref) } \\
1.36\end{array}$ & $(1.01-1.83)$ \\
\hline Labour migrant & $\begin{array}{l}\text { No } \\
\text { Yes }\end{array}$ & 0.067 & $\begin{array}{l}\text { (ref) } \\
1.36\end{array}$ & $(0.98-1.88)$ \\
\hline Diabetes & $\begin{array}{l}\text { No } \\
\text { Yes }\end{array}$ & 0.066 & $\begin{array}{l}\text { (ref) } \\
1.59\end{array}$ & $(0.97-2.61)$ \\
\hline $\mathrm{HCV}$ & $\begin{array}{l}\text { No } \\
\text { Yes }\end{array}$ & 0.540 & $\begin{array}{l}\text { (ref) } \\
1.12\end{array}$ & $(0.79-1.59)$ \\
\hline Resistance category & $\begin{array}{l}\text { RR/MDR } \\
\text { Other } \\
\text { Pre-XDR } \\
\text { XDR } \\
\end{array}$ & $\begin{aligned} & 0.378 \\
&< \mathbf{0 . 0 0 1} \\
&< \mathbf{0 . 0 0 1} \\
&\end{aligned}$ & $\begin{array}{l}\text { (ref) } \\
1.35 \\
\mathbf{3 . 1 3} \\
\mathbf{4 . 0 8}\end{array}$ & $\begin{array}{c}(0.69-2.66) \\
(\mathbf{2 . 1 6 - 4 . 5 5 )} \\
(\mathbf{2 . 4 5 - 6 . 7 9 )}\end{array}$ \\
\hline Home-based treatment & $\begin{array}{l}\text { No } \\
\text { Yes }\end{array}$ & 0.001 & $\begin{array}{l}\text { (ref) } \\
\mathbf{0 . 4 5}\end{array}$ & $(0.28-0.72)$ \\
\hline Treatment with new drugs & $\begin{array}{l}\text { No } \\
\text { Yes }\end{array}$ & $<0.001$ & $\begin{array}{l}\text { (ref) } \\
\mathbf{0 . 2 6}\end{array}$ & $(0.18-0.39)$ \\
\hline
\end{tabular}

HR, hazards ratio; CI, confidence interval; DST, drug susceptibility test; RRMDR, rifampicin resistant/multidrug resistant; pre-XDR, pre-extensively drug resistant; XDR, extensively drug resistant. 
supervision of DOT despite the existing guidelines [40,41].

Based on the evidence of improved treatment outcomes and reduced mortality, the new drugs containing treatment regimens were further approved in the framework of the End TB strategy and the national treatment guidelines since 2016 [42-44]. Our study findings are in line with the existing literature and show reduction of risk of unfavourable treatment outcomes among difficult-to-treat RR/MDR-TB patients receiving bedaquiline and delamanid compared to those who were on conventional treatment regimens [45-47]. State registration of delamanid by the National Scientific Center of Drug and Medical Technology Expertise and inclusion of both bedaquiline and delamanid into the list essential medicines is still pending [48]. A comparative study exploring the difference between the treatment success rate and unfavourable treatment outcomes in a cohort of RR/MDR-TB patients received conventional treatment and treatment containing new drugs would pave a way to a prompter solution of the mentioned issue.

In the unadjusted analyses, we found a strong association between labour migration and unfavourable outcomes. Nevertheless, this association lost significance when controlled for the effect of other variables. It is estimated that in general population the percentage of 'labour migrants' is $6.5 \%$ [26] whereas in our cohort it was $28.6 \%$. This figure - almost 4.4 times higher than the same estimate for the general population - indicates that our study participants represent the most vulnerable groups in the country even though official data on socio-economic status of RR/MDR-TB patients is missing. In their study Truzyan et al. showed higher risk for developing multidrug resistance, prolonged time between diagnosis and treatment initiation and treatment interruption among migrant workers with TB in Armenia [49].

Our study has the following limitations: the data about adverse events were not available, thus, it was not possible to evaluate their impact on home-based DOT, which is the main factor against this mode of treatment in the literature. In addition, the variables such as current smoking status and migrant status were self-reported which may have led to potential information bias. One of the strengths of our study is that it included a nationwide cohort from 2014-2017. Data captured from 'e-TB manager' system were of good quality and contained very few errors and missing data.

The RR/MDR-TB is a challenge in Armenia. The favourable treatment outcome in the nationwide cohort of 2014-2017 was far below the recommended threshold. The most common unfavourable treatment outcome was LTFU and further research is needed to better understand the factors leading to treatment interruptions. Expanding home-based DOT and administration of new drugs may open up new perspectives for improving treatment outcomes in RR/MDR-TB patients.

\section{References}

1. WHO. Global tuberculosis report 2019. Geneva: World Health Organization; 2019. Accessed on: 2019 Nov 22. Available from: https://www.who.int/tb/publications/global_report/en/

2. Acosta CD, Dadu A, Ramsay A, et al. Drug-resistant tuberculosis in Eastern Europe: challenges and ways forward. Public Heal Action 2014;4:S3-12.

3. WHO. Armenia country review report 2019. Geneva: World Health Organization; 2019.

4. WHO Regional Office for Europe. Tuberculosis surveillance and monitoring report in Europe 2019. Accessed 2020 Jul 1. Available from: https://www.euro.who.int/en/health-topics/ communicable-diseases/tuberculosis/publications/2019/tuberculosis-surveillance-and-monitoring-report-in-europe-2019

5. WHO. Armenia TB profile 2018. Geneva: World Health Organization; 2019.

6. Migliori GB, Tiberi S, Zumla A, et al. MDR/XDR-TB management of patients and contacts: challenges facing the new decade. The 2020 clinical update by the global tuberculosis network. Int J Infect Dis 2020;92:S15-25.

7. Woldeyohannes D, Assefa T, Aman R, et al. Predictors of time to unfavorable treatment outcomes among patients with multidrug resistant tuberculosis in Oromia region, Ethiopia. PLoS One 2019;14:e0224025.

8. Alffenaar JWC, Akkerman OW, Kim HY, et al. Precision and personalized medicine and anti-tb treatment: is tdm feasible for programmatic use? Int J Infect Dis 2020;92:S5-9.

9. Sanchez-Padilla E, Marquer C, Kalon S, et al. Reasons for defaulting from drug-resistant tuberculosis treatment in armenia: a quantitative and qualitative study. Int J Tuberc Lung Dis 2014;18:160-7.

10. Chem ED, Van Hout MC, Hope V. Treatment outcomes and antiretroviral uptake in multidrug-resistant tuberculosis and HIV co-infected patients in sub-Saharan Africa: a systematic review and meta-analysis. BMC Infect Dis 2019;19:723.

11. Verdecchia M, Keus K, Blankley S, et al. Model of care and risk factors for poor outcomes in patients on multi-drug resistant tuberculosis treatment at two facilities in Eswatini (formerly Swaziland), 2011-2013. PLoS One 2018;13:e0205601.

12. Huangfu P, Ugarte-Gil C, Golub J, et al. The effects of diabetes on tuberculosis treatment outcomes: an updated systematic review and meta-analysis. Int J Tuberc Lung Dis 2019;23:783-96.

13. Choi H, Lee M, Chen RY, et al. Predictors of pulmonary tuberculosis treatment outcomes in South Korea: a prospective cohort study, 2005-2012. BMC Infect Dis 2014;14:360.

14. Parmar MM, Sachdeva KS, Dewan PK, et al. Unacceptable treatment outcomes and associated factors among India's initial cohorts of multidrug-resistant tuberculosis (MDR-TB) patients under the revised national TB control programme (2007-2011): evidence leading to policy enhancement. PLoS One 2018;13:e0193903.

15. Htun YM, Khaing TMM, Aung NM, et al. Delay in treatment initiation and treatment outcomes among adult patients with multidrug-resistant tuberculosis at Yangon regional tuberculosis centre, Myanmar: a retrospective study. PLoS One 2018;13: e0209932.

16. Phuong NTM, Nhung NV, Hoa NB, et al. Management and treatment outcomes of patients enrolled in mdr-tb treatment in viet nam. Public Heal Action 2016;6:25-31.

17. Alegria-Flores $\mathrm{K}$, Weiner BJ, Wiesen CA, et al. Innovative approach to the design and evaluation of treatment adherence interventions for drug-resistant TB. Int $\mathrm{J}$ Tuberc Lung Dis 2017;21:1160-1.

18. Bastard M, Sanchez-Padilla E, Hewison C, et al. Effects of treatment interruption patterns on treatment success among patients with multidrug-resistant tuberculosis in Armenia and Abkhazia. J Infect Dis 2015;211:1607-15.

19. Bastard M, Sanchez-Padilla E, Du Cros P, et al. Outcomes of HIV-infected versus HIV-non-infected patients treated for drug-resistance tuberculosis: multicenter cohort study. PLoS One 2018;13: e0193491.

20. Ministry of Health of the Republic of Armenia. National tuberculosis strategy 2016-20. Accessed on: 2020 Aug 5. Available from: http://www.irtek.am/views/act.aspx?aid=84463 
21. WHO. Review of financial sustainability of tuberculosis activities in Armenia. Accessed on: 2020 Jul 1. Available from: https://www.euro.who.int/_data/assets/pdf_file/0006/376998/ armenia-fin-sust-tb-eng.pdf

22. WHO. Rapid communication: key changes to the treatment of drug-resistant tuberculosis. 2019. Accessed on: $2020 \mathrm{Jul} 1$. Available from: https://www.who.int/tb/publications/2019/ WHO_RapidCommunicationMDR_TB2019.pdf?ua=1

23. WHO. Introduction of bedaquiline for the treatment of multidrug-resistant tuberculosis at country level. Accessed on: 2020 Jul 1. Available from: https://www.who.int/tb/publications/2015/Bedaquiline_implementation_plan.pdf?ua=1

24. WHO. Consolidated guidelines on the use of antiretroviral drugs for treating and preventing HIV infection. 2016. Accessed on: $2020 \mathrm{Jul} 1$. Available from: https://apps.who.int/ iris/bitstream/handle/10665/208825/9789241549684_eng.pdf; jsessionid $=$ CFDC692E793B2858A95868810F57808A?seque nce $=1$

25. Avaliani Z, Gozalov O, Kuchukhidze G, et al. What is behind programmatic treatment outcome definitions for tuberculosis? Eur Res J 2020;56 2001751.

26. International Labour Organization (ILO). Migration and development Armenia country study, 2009. Accessed on: 2020 Jun 29. Available from: http://www.un.am/up/library/Migr_Dev_ Study_eng.pdf

27. Muñnoz-Torrico M, Luna JC, Migliori GB, et al. Comparison of bacteriological conversion and treatment outcomes among mdr-tb patients with and without diabetes in mexico: preliminary data. Rev Port Pneumol 2017;23:27-30.

28. Atif M, Bashir A, Ahmad N, et al. Predictors of unsuccessful interim treatment outcomes of multidrug resistant tuberculosis patients. BMC Infect Dis 2017;17:655.

29. Leveri TH, Lekule I, Mollel E, et al. Predictors of treatment outcomes among multidrug resistant tuberculosis patients in Tanzania. Tuberc Res Treat 2019;2019:3569018.

30. Makhmudova M, Maxsumova Z, Rajabzoda A, et al. Risk factors for unfavourable treatment outcomes among rifampicinresistant tuberculosis patients in Tajikistan. Int J Tuberc Lung Dis 2019;23:331-6.

31. Tola HH, Shojaeizadeh D, Garmaroudi G, et al. Psychological distress and its effect on tuberculosis treatment outcomes in Ethiopia. Glob Health Action 2015;8:29019.

32. Merid MW, Gezie LD, Kassa GM, et al. Incidence and predictors of major adverse drug events among drug-resistant tuberculosis patients on second-line anti-tuberculosis treatment in Amhara regional state public hospitals; Ethiopia: a retrospective cohort study. BMC Infect Dis 2019;19:286.

33. Zhang Y, Wu S, Xia Y, et al. Adverse events associated with treatment of multidrug-resistant tuberculosis in china: an ambispective cohort study. Med Sci Monit 2017;23:2348-56.

34. Alene KA, Yi H, Viney $\mathrm{K}$, et al. Treatment outcomes of patients with multidrug-resistant and extensively drug resistant tuberculosis in Hunan Province, China. BMC Infect Dis 2017; 17:573.

35. Migliori GB, Nardell E, Yedilbayev A, et al. Reducing tuber- culosis transmission: a consensus document from the World Health Organization Regional Office for Europe. Eur Respir J 2019;53:1900391.

36. Khachadourian V, Truzyan N, Harutyunyan A, et al. Peoplecentered tuberculosis care versus standard directly observed therapy: study protocol for a cluster randomized controlled trial. Trials 2015;16:281.

37. Ravenscroft L, Kettle S, Persian R, et al. Video-observed therapy and medication adherence for tuberculosis patients: randomised controlled trial in Moldova. Eur Respir J 2020;56: 2000493.

38. Sinkou H, Hurevich H, Rusovich V, et al. Video-observed treatment for tuberculosis patients in Belarus: findings from the first programmatic experience. Eur Res J 2017;49: 1602049.

39. Wade VA, Karnon J, Eliott JA, et al. Home videophones improve direct observation in tuberculosis treatment: a mixed methods evaluation. PLoS One 2012;7:e50155.

40. Horter S, Stringer B, Reynolds L, et al. "Home is where the patient is": a qualitative analysis of a patient-centred model of care for multi-drug resistant tuberculosis. BMC Health Serv Res 2014;14:81.

41. Mhimbira F, Hella J, Maroa T, et al. Home-based and facilitybased directly observed therapy of tuberculosis treatment under programmatic conditions in urban Tanzania. PLoS One 2016;11:e0161171.

42. Bastard M, Guglielmetti L, Huerga H, et al. Bedaquiline and repurposed drugs for fluoroquinolone-resistant multidrugresistant tuberculosis: how much better are they? Am J Res Care 2018;198:1228-31.

43. Hewison C, Bastard M, Khachatryan N, et al. Is 6 months of bedaquiline enough? Results from the compassionate use of bedaquiline in Armenia and Georgia. Int J Tuberc Lung Dis 2018;22:766-72.

44. Mbuagbaw L, Guglielmetti L, Hewison C, et al. Outcomes of bedaquiline treatment in patients with multidrug-resistant tuberculosis. Emerg Infect Dis 2019;25:936-43.

45. Bonnet M, Bastard M, Du Cros P, et al. Identification of patients who could benefit from bedaquiline or delamanid: a multisite MDR-TB cohort study. Int J Tuberc Lung Dis 2016;20:177-86.

46. Skripconoka V, Danilovits M, Pehme L, et al. Delamanid improves outcomes and reduces mortality in multidrug-resistant tuberculosis. Eur Respir J 2013;41:1393-400.

47. Kuksa L, Barkane L, Hittel N, et al. Final treatment outcomes of multidrugand extensively drug-resistant tuberculosis patients in Latvia receiving delamanid-containing regimens. Eur Res J 2017;50.

48. List of essential medicines of ra [Internet]. Accessed on: 2020 Jul 1. Available from: http://digicollection.org/hss/documents/s17079e/s17079e.pdf

49. Truzyan N, Crape B, Grigoryan R, et al. Increased risk for multidrug-resistant tuberculosis in migratory workers, Armenia. Emerg Infect Dis 2015;21:474-6. 